Review Article

\title{
Skeletal and Neurological Features of Seckel Syndrome and Microcephalic Osteodysplastic Primodrial Dwarfism - A Review of the Literature
}

\author{
Abd-Alla Mona ${ }^{1}$, Koenigs Ingo ${ }^{2}$, Fritzsche Sophie Friederike ${ }^{3}$, Kloth Katja ${ }^{4}$, Singer Dominique ${ }^{5}$, \\ Reinshagen Konrad², Trah Julian", * \\ ${ }^{1}$ School of Medicine, University Medical Center Hamburg-Eppendorf, Hamburg, Germany \\ ${ }^{2}$ Department and Clinic of Pediatric Surgery, University Medical Center Hamburg-Eppendorf, Hamburg, Germany \\ ${ }^{3}$ Department of Neurosurgery, University Medical Center Hamburg-Eppendorf, Hamburg, Germany \\ ${ }^{4}$ Department of Pediatric Hematology and Oncology, University Medical Center Hamburg-Eppendorf, Hamburg, Germany \\ ${ }^{5}$ Division of Neonatology and Pediatric Intensive Care Medicine, University Medical Center Hamburg-Eppendorf, Hamburg, Germany
}

Email address:

jtrah@uke.de (T. Julian)

${ }^{*}$ Corresponding author

\section{To cite this article:}

Abd-Alla Mona, Koenigs Ingo, Fritzsche Sophie Friederike, Kloth Katja, Singer Dominique, Reinshagen Konrad, Trah Julian. Skeletal and Neurological Features of Seckel Syndrome and Microcephalic Osteodysplastic Primodrial Dwarfism - A Review of the Literature. American Journal of Pediatrics. Vol. 6, No. 3, 2020, pp. 373-380. doi: 10.11648/j.ajp.20200603.44

Received: July 6, 2020; Accepted: August 3, 2020; Published: September 10, 2020

\begin{abstract}
Backround: Primordial dwarfism is a rare disease pattern that is notable due to its clinical appearance. The first description was made in 1960 and created the initial image of the "bird-like" face with severe growth retardation. The condition then was called Seckel syndrome. However, not every child with primordial dwarfism met the criteria of Seckel syndrome; hence a sub-classification of microcephalic osteodysplastic primordial dwarfism (MOPD) was introduced. This in turn caused far-reaching confusion because many of the mentioned manifestations overlapped. Objectives: By this study the authors try to identify syndrome specific features for the respective clinical pictures with focus on skeletal changes and the associated neurological risks. Method: Medical Databases search was done for the Keywords: Seckel Syndrome, MOPD and Microcephalic Osteoplastic Primordial Dwarfism. All Articles until 2020 were included with special attention to case and case control studies. Results: Some clinical features or the common appearance of features appear to make a clear differentiation of Seckel syndrome, MOPD I/III and MOPD II possible. Conclusion: This review aims to highlight the differences in the morphological and skeletal appearances and to represent possible associated neurological co-morbidities that require special observation. Although for detailed differentiation genetic analyses of associated mutations might be the only.
\end{abstract}

Keywords: Seckel Syndrome, Microcephalic Osteodysplastic Primordial Dwarfism, MOPD, Dwarfism, Bird-headed

\section{Introduction}

Primordial dwarfism is defined as severe intrauterine and postnatal dwarfism, severe microcephaly, proportionate smallness of skull and face, severe mental retardation and some other anomalies that are observed in addition to the "bird-like" shape of the face. "Bird-like" describes the protrusion of the nose, narrowness of the face and recession of the lower jaw and chin. [1]
The initial description of primordial dwarfism was mainly applied to children with Seckel syndrome. But it is quite heterogeneous in its expression and later three more types were defined and named microcephalic osteodysplastic primordial dwarfism (MOPD). They have similar aspects, but different radiological findings. [2] Later MOPD I and III were classified as possible variants of the same disorder. [3-6] Only a small number of the cases in the literature meet all the diagnostic criteria. 
More than 200 cases of Seckel syndrome, more than 70 cases of MOPD I/III and over 120 cases of MOPD II have been described in the literature so far. $[2,7,8]$

In addition to the obvious changes, primordial dwarfism has also been linked to numerous cerebral vascular anomalies. These play an important role in the follow-up and risk assessment of patients.

This study aims to identify typical features of the four entities by highliting the morphological and neurological changes in every disease pattern.

Prenatal diagnosis

For all classifications of MOPD, intrauterine growth retardation (IUGR) is reported in the prenatal ultrasound. [912] Brain anomalies such as microcephaly, hypoplastic cerebrum with porencephalic cyst, dilated ventricles, arachnoid cysts and hydrocephalus have been described. [10, $13,14]$ In cases of Seckel syndrome, even facial dysmorphisms such as beaked nose, hypotelorism and micrognathia are seen in prenatal scans. [10, 15] Furthermore, low-set ears, small long bones and clindodactyly of the little finger can be observed before birth. [12] Magnetic resonance imaging (MRI) of an unborn baby suspected to have MOPD can show smooth gyri and multiple brain cysts. $[10,11,15]$

Dysmorphism

All syndromes show heterogeneous but similar "bird-like" facial dysmorphisms. [4-6] Nevertheless, the combination of a narrow face, a prominent beak-like nose and recession of the lower jaw and chin is most common in Seckel syndrome. Additionally, these patients often show abnormally shaped or hypoplastic low-set ears and receding or sloping foreheads. [16-23] A MOPD II patient typically presents with a prominent nose that exhibits a prominent nasal root and bridge, and a receding forehead. Patients with MOPD I/III most frequently show small, abnormally shaped low-set ears; prominent, large, protruding eyes; prominent noses; and frequently, sparse eyebrows and lashes. Anomalies of the ears are described less often in patients with MOPD II and Seckel syndrome. However, the facial dysmorphisms of all three syndromes are quite similar, so that patients with forms of microcephalic primordial dwarfism cannot be differentiated by their facial appearances alone.

\section{Skeletal Features}

\subsection{Seckel Syndrome}

On physical examination, patients with Seckel syndrome show characteristically proportionate short statures. [20, 24 26] Some patients show a particular stance that is characterised by flexion at the hips and pronation of the forearms. [27] Contractures of the hips, the knees and the elbows have been described, as well as dysplastic or/and luxation of the hips and coxa vara and valga. [10, 24, 28-31] A variety of foot anomalies such as congenital talipes equinovarus, pes planus, metatarsus adductus, sandal toe deformity and syndactyly of the second and third toes have been described. [25, 30, 32-35] Clinodactyly of the little finger is one of the most commonly found anomalies in children with Seckel syndrome. [15] Some patients show brachydactyly, arachnodactyly or a simian crease. Early closure of anterior and posterior fontanelles, and as a result fontanelles that are not palpable, are often seen. [27, 31, 36] Pectus excavatum, scoliosis, posteriorly angulated ribs, short sternum and 11 pairs of ribs are common trunk anomalies. [26, $31,33,37,38]$ Delayed bone age and osteoporotic changes are often seen on radiographic examination. [20, 25, 33, 37, 39] In some cases, there have been reports of mild bowing of the radius head, chevron deformity of the lower end of the femora, narrow iliac blades, radius hypoplasia, epiphysiolysis in the distal femur, slight clubbing and ill-defined epiphysis in the tubular bones, and deformed acetabular roofs; however, these are more characteristic of MOPD. [17, 27, 40]

\subsection{MOPD II}

Small skulls with hypoplasia of the mandibles and precocious closure of the cranial sutures are described in patients with MOPD II. [31, 41-44] The stature of a MOPD II patient appears short with disproportional short limbs that can be hypermobile. The hands, fingers and underarms show ulnar deviation and sometimes a bilateral simian crease, syndactyly, or clinodactyly of the fifth digit. Brachydactyly, brachytelephalangia I-V, brachymesophalangia II-V, brachymetacarpalia, as well as other anomalies such as pseudoepiphysis of the metacarpals, irregular shape of the epiphyses, ivory epiphyses, hypoplastic distal phalanges and anomalies of the carpal bones, are common characteristics of MOPD II. [41, 42, 45] The long bones appear slender and overtubulated. The pelvis may be hypoplastic with narrow iliac wings, and in some cases the acetabular angle is dysmorphic. Affected individuals frequently show coxa vara and, more rarely, coxa valga. Dislocations of the knees, the elbows and especially of the hips are quite typical. [31, 42, 44, 45]

In a MOPD II patient, the femoral metaphyses flares is widened and is irregularly formed (V-shaped or delta-shaped), while the femoral epiphyses are described as irregular and as triangular or cone-shaped. The radius and ulna bones are short and mildly bowed. [41, 46, 47] Anomalies of the trunk are less common in MOPD II, but in some cases the clavicles are elongated, the scapula is hypoplastic, the chest is narrow, and the number of ribs is decreased from the normal. [43, 48]

\subsection{MOPD I/III}

Patients with MOPD I/III show small skulls with steep and sclerotic cranial bases. $[49,50]$ The anterior fontanelles may be small or missing due to early closure. [43, 51] Disproportionately short limbs are quite common, with small hands or feet and short fingers and toes, as well as short and broad necks. [7, 49, 50, 52, 53] The hands and feet may show dorsal oedema and give the impression of loose skin. The fingers are described as fusiform or tapering and the thumbs as hypoplastic or low-set. Single transverse palmar creases, clinodactyly (of the little fingers), and dysplastic nails are 
other anomalies seen, as well as rocker-bottom feet and equinovalgus feet. [49, 50, 52-55] Contractures of the knees, elbows and necks are described, as well as genu valgum and ulnar deviation at the wrists. [3, 7, 43]

In radiographic examination the long bones appear short and bowed. The metaphysis of femora, tibiae and humeri seem broad with irregular ends, and the ossification of several bones (as femora, tali, calcanei, pubic bones, and sternal segments) is missing or inadequate. [49, 50, 53, 56] Bone aging is in general delayed. [43, 48] Platyspondyly, horizontal acetabular roofs, elongated clavicles as well as narrow pelvises with hypoplastic iliac wings are characteristics of MOPD I/III. Pectus excavatum, pectus carinatum and abnormal ribs have also been described in patients with MOPD I/III, but they are rarer than the previously described anomalies. [49, 53, 56, 57] More common than thoracic anomalies are the dislocations of knees, hips and elbows. [3, 6]

\section{Neurological Findings and Brain Anomalies}

\subsection{Seckel Syndrome}

A Seckel syndrome patient quite often presents with a small cerebrum that exhibits cerebral atrophy, a simplified gyral pattern, dilated ventricles and/or hypoplastic corpus callosum in radiological examination. [22, 23, 58, 59] The cerebrum is hypoplastic or atrophic and may seem even comparatively large. [60] There are at least two reports regarding patients with Seckel syndrome who have shown cerebellar tonsillar herniation, as well as two reports about semilobar holoprosencephaly in patients with the syndrome and one that describes non-cleavage of the basal ganglia and the frontal lobe. [36, 59, 61, 62] MRI has shown reduction of the white matter, in contrast with the grey matter that has been described as thickened. Just as in patients with MOPD I/III, brain cysts have been found. Clinically, patients may present with generalised hypotonia, hypertonia and/or hyperreflexia. Occurrences of seizures not related to fever or to cerebral haemorrhage have been reported. [22, 23, 29, 63] The absence of the adenohypophysis has been reported in autopsies, as well as cortical neuronal migration disorder, white matter tract hypoplasia, and premature depletion of the germinal matrix with cystic transformation and patchy absence of the external granular cell layer of the cerebellum. [64] Seckel syndrome in general shows a large range of manifestations of brain anomalies, but the brain imaging has also been described as normal. [17, 18, 24, 29] Seckel syndrome is quite often associated with vascular anomalies of the central nervous system. Aneurysms are common in Seckel syndrome patients, and are detected mostly by the symptoms of cerebral haemorrhage. Some patients have shown acute respiratory failure, seizures or abrupt-onset coma. Others have presented with headaches, numbness in the limbs or hemiparesis. So far in three cases the angiographic findings have been consistent even with "moyamoya" disease, but this consistency is rare compared with that shown for MOPD II. Patients have even shown infarction in the right frontal region due to polyarteritis nodosa, but this is very rare; indeed, it has been described only once. [34, 35, 40, 72-74]

\subsection{MOPD II}

The most common radiological anomalies that have been reported are the enlargement of the ventricles, the hypoplasia/ thinning of the corpus callosum (especially of the anterior part), and anomalies of the gyral pattern such as pachygyria and polymicrogyria. [65-67] The ventricular system may also seem dysmorphic. Overall, the cerebellum is small or atrophic, while the cerebrum may be of normal size or slightly atrophic. The myelination may be delayed, and the cortical thickness increased. The basic structure of the cerebral cortex is normal. [66-68]

Neurological examination may show hypertonia. Due to premature fusion of the cranial sutures, patients may show signs of increased intracranial pressure. In all cases that have been analysed, there is only one report regarding a non-haemorrhagic seizure disorder. [65, 69]

Vascular anomalies such as "moyamoya" disease seem to be common in patients with MOPD II. These patients are detected mostly by clinical symptoms of stroke, but may be detected by routine scanning. Detection is not always easy; typical vascular anomalies such as narrowing of the bilateral intracranial supraclinoidal internal carotid arteries and the "moyamoya" collaterals have been found to become prominent only at follow-up examinations. Some patients show intracranial haemorrhage caused by ruptured aneurysms without having intracranial vascular changes that would be consistent with "moyamoya" disease, or they have become symptomatic through stenosis of intracranial arteries. [75-77]

\subsection{MOPD I/III}

MOPD I/III patients often show small cerebra with atrophy and prominent abnormal gyral patterns, particularly pachygyria. In a MOPD I/III patient, the cerebellum may seem malformed and hypoplastic with cortical atrophy. Anomalies of the corpus callosum are typical in MOPD I/III; a partial or complete agenesis is especially frequent, or at least a significant reduction in size is observed, although less often. An agenesis or a hypoplasia of the vermis, an interhemispheric cyst and dilated ventricles are also seen in affected people. [3, $6,7,26,49,52,54]$ On neurological examination, hypotonia or hypertonia and brisk reflexes may be noticed. Seizures that are not related to fever or to cerebral haemorrhage are more common in MOPD I/III than in MOPD II. [70, 71] In pathological biopsies, it is often seen that the cortical architecture is abnormal with irregular and disorganised distribution of neurons and acute infarction areas; quite often necrotic foci can be found as well. [70] At least two cases of MOPD I/III have been reported in which intracranial aneurysms were associated with the condition, and two other MOPD I/III patients have been reported to have suffered acute infarctions that showed up in cranial computed tomography or autopsy. $[6,51,55]$ To our knowledge, no reported case has 
been associated with "moyamoya" disease.

\section{Genetic Background}

Recently a large study identified several genes that could help to divide primordial dwarfism into its sub-groups. However, even with knowledge about these genes, a clear distinction between the groups seems to be impossible as some of the genes were found in more than one of the examined individuals who were classified as belonging to different subtypes through use of the clinical differentiations. [78]

\subsection{Seckel Syndrome}

In contrast with MOPD I/III and MOPD II, more than one gene has been identified as being involved in causing Seckel syndrome. The first mutation to be described was in the SCKL1 gene. Later the mutation of the gene in that locus that encodes for ataxia telangiectasia and Rad3-related protein (ATR) was described as the cause of Seckel syndrome. [27, 29] Another locus was identified in 2001 in the CtIP (RBBP8) gene, which is involved in the repair of DNA double-strand breaks. [79] Further mutations were found on the CENPJ, CEP152 and CEP63 genes. [17, 33, 80] Shaheen et al. described in 2014 a new mutation that caused Seckel syndrome; this mutation was found in the DNA2 gene. [64] Pericentrin (PCNT) mutation, which was described previously in MOPD II patients, was subsequently found in five of 16 families who were analysed as they showed clinical symptoms of Seckel syndrome. The Seckel syndrome patients identified with PCNT mutations showed more severe growth retardation, but nonetheless their retardation was less severe than that observed in the MOPD II patients. [31]

Mutations in the TRAIP and PLK4 genes have also been revealed to be part of the cause of Seckel syndrome. [71, 81]
Other mutations in patients with primordial dwarfism have been seen on chromosome 8q24 in the NSMCE2 gene, the knockout of which has induced dwarfism in zebrafish, and on chromosome 14q22.1 in the NIN gene. The NIN gene mutation was identified in two siblings who presented with clinical features of microcephalic primordial dwarfism that were not consistent with MOPD II or Seckel syndrome. It has been shown in zebrafish that a reduced function of the ninein protein encoded by the NIN gene leads to specific deficiencies of brain and skull development. [82]

\subsection{MOPD II}

In several studies and case reports, genomic analyses of patients and families with clinical diagnoses of MOPD II have revealed mutations in the PCNT gene. Other patients diagnosed with MOPD I/III, Seckel syndrome or unclassified growth retardation syndromes have not shown any PCNT mutations. [31, 83]

\subsection{MOPD I/III}

In 2011, a mutation in the RNU4ATAC gene was described for the first time in patients with MOPD I/III. This gene was later described as mutated in reports of several patients and families. [7, 54, 84]

\section{Conclusion}

Some clinical features or the common appearance of features appear to make a clear differentiation of Seckel syndrome, MOPD I/III and MOPD II possible (Table 1). Although for most symptoms, this report shows that the clinical manifestations overlap and that a clear assignment to one of these subgroups sometimes does not seem possible.

Table 1. Common Skeletal and Neurological Findings.

\begin{tabular}{lll}
\hline Common Skeletal Findings & MOPD I/III & MOPD II \\
\hline Seckel Syndrom & $\begin{array}{l}\text { disproportionately short limbs } \\
\text { small hands or feet } \\
\text { short fingers and toes } \\
\text { short and broad neck } \\
\text { dislocation of knees } \\
\text { dislocation of the hip } \\
\text { dislocation of the elbows } \\
\text { platyspondyly } \\
\text { horizontal acetabular roofs } \\
\text { elongated clavicles } \\
\text { narrow pelvis }\end{array}$ & $\begin{array}{l}\text { pseudoepiphysis of the metacarpals } \\
\text { irregular shape of the epiphyses } \\
\text { ivory epiphyses } \\
\text { hypoplastic distal phalanges } \\
\text { anomalies of the carpal bones } \\
\text { dislocation of the hip } \\
\text { disproportional short limbs }\end{array}$ \\
\hline fifth finger clinodactyly & & \\
\hline Common Neurological Findings & & \\
\hline Seckel Syndrom & MOPD I/III & \\
\hline small cerebrum with cerebral atrophy & $\begin{array}{l}\text { small cerebrum with atrophy } \\
\text { prominent abnormal gyral pattern } \\
\text { pachygyria }\end{array}$ & $\begin{array}{l}\text { MOPD II } \\
\text { enlargement of the ventricles } \\
\text { hypoplasia/ thinning of the corpus callosum (especially of the anterior part) } \\
\text { pachygyria and polymicrogyria }\end{array}$ \\
\hline
\end{tabular}

All three syndromes show significant similarities; however, they also display substantial differences. These differences are mostly seen in their skeletal features as disproportionately short limbs in MOPD II, or as platyspondyly, horizontal 
acetabular roofs, elongated clavicles, and a narrow pelvis in MOPD I/III.

It is important to note that MOPD II patients have been initially misdiagnosed with Seckel syndrome, due to their displays of intrauterine growth retardation and typical facial features. Therefore, one should consider re-evaluation of Seckel syndrome cases that have been described with osteodysplastic features and perform genomic tests if not already done. In general, differential diagnosis of microcephalic dwarfism as LIG4 syndrome, Russell-Silver syndrome, 3-M syndrome, Antley-Bixler syndrome or Faconi syndrome should be considered and excluded before offering a diagnosis of one of the three discussed syndromes.

The large number of genes that has been found to be involved in causing MOPD offers promise in the differentiation of the syndromes through genetic analysis. An evaluation of the influence of the causal gene mutation and additional clinical features seems promising. An evaluation of this type was performed by Willem et al. with Seckel syndrome patients whose PCNT status was studied. Furthermore, such an evaluation could offer further information regarding the chances of occurrence of accompanying diseases, such as pancytopenia, intracranial haemorrhages or cardiac disease, that are often associated in these patients.

This review underlines the importance of extensive examination of patients to seek the right diagnoses, which are necessary for the correct risk analysis of cerebral vascular comorbidities such as infarction or "moyamoya" disease.

\section{Authors' Contributions}

MA - substantional contribution to the conception, design of work, analysis

IK - analysis and interpretation of data

FF - analysis and interpretation of data

KK - analysis and interpretation of data

DS - made substantial contribution to the conception and substantively revised

$\mathrm{KR}$ - made substantial contribution to the conception and substantively revised

JT - Made substantial contribution to the conception and substantively revised, design of work, drafted the work

\section{Ethics Approval and Consent to Participate}

Not applicable.

\section{Consent for Publication}

Not applicable.

\section{Availability of Data and Materials}

Not applicable.

\section{Funding}

No Funding resource.

\section{Declaration of Interest}

None.

\section{Competing Interests}

The authors declare that they have no competing interests.

\section{Acknowledgements}

All authors approved the submitted version and agreed both to be personally accountable for the author's own contributions and to ensure that questions related to the accuracy or integrity of any part of the work, even ones in which the author was not personally involved, are appropriately investigated, resolved, and the resolution documented in the literature.

\section{References}

[1] Seckel, H. P. 'Premature thelarche' and 'premature metratarch' followed by normal adolescence. J. Pediatr. 57, 204-209 (1960).

[2] Majewski, F., \& Goecke, T. Studies of microcephalic primordial dwarfism I: approach to a delineation of the Seckel syndrome. Am. J. Med. Genet. 12, 7-21 (1982).

[3] Haan, E. A., et al. Osteodysplastic primordial dwarfism: report of a further case with manifestations similar to those of types I and III. Am. J. Med. Genet. 33, 224-227 (1989).

[4] Meinecke, P., \& Passarge, E. Microcephalic osteodysplastic primordial dwarfism type I/III in sibs. J. Med. Genet. 28, 795800 (1991).

[5] Meinecke, P., Schaefer, E., \& Wiedemann, H. R. Microcephalic osteodysplastic primordial dwarfism: further evidence for identity of the so-called types I and III. Am. J. Med. Genet. 39, 232-236 (1991).

[6] Winter, R. M., Wigglesworth, J., \& Harding, B. N. Osteodysplastic primordial dwarfism: report of a further patient with manifestations similar to those seen in patients with types I and III. Am. J. Med. Genet. 21, 569-574 (1985).

[7] Pakseresht, S., et al. Microcephalic Osteodysplastic Primordial Dwarfism Type I in Two Siblings Aged 2.5 Years and 18 Gestational Weeks. Genet. 3rd Millenn. 13, 3970-3975 (2015).

[8] Vardhan, B. H., Muthu, M. S., Saraswathi, K., \& Koteeswaran, D. Bird-Headed Dwarf of Seckel. J. Indian Soc. Pedod. Prev. Dent. 25, 8 (2007).

[9] Kilic, A., et al. Seckel syndrome with cutaneous pigmentary changes: two siblings and a review of the literature. Postepy Dermatol. Alergol. 32, 470-474 (2015).

[10] Napolitano, R., Maruotti, G. M., Quarantelli, M., Martinelli, P., \& Paladini, D. Prenatal diagnosis of Seckel Syndrome on 3-dimensional sonography and magnetic resonance imaging. $J$. Ultrasound Med. Off. J. Am. Inst. Ultrasound Med. 28, 369374 (2009). 
[11] Takikawa, K. M., et al. Perinatal findings of Seckel syndrome: a case report of a fetus showing primordial dwarfism and severe microcephaly. Fetal Diagn. Ther. 24, 405-408 (2008).

[12] Vascone, C., et al. Antenatal diagnosis of Seckel Syndrome: a rare case report. J. Prenat. Med. 8, 70-72 (2014).

[13] Bhutia, E., Verma, A., Gupta, A. K., \& Maria, A. An unusual association of microcephalic osteodysplastic primordial dwarfism type I with cardiac and brain anomalies. J. Clin. Neonatol. 3, 53-54 (2014).

[14] Majoor-Krakauer, D. F., Wladimiroff, J. W., Stewart, P. A., van de Harten, J. J., \& Niermeijer, M. F. Microcephaly, micrognathia, and bird-headed dwarfism: prenatal diagnosis of a Seckel-like syndrome. Am. J. Med. Genet. 27, 183-188 (1987).

[15] Gupta, A., Fazal, T. S., \& Arora, R. Antenatal Diagnosis of Seckel Syndrome. J. Obstet. Gynaecol. India 64, 6-8 (2014).

[16] Aktas, Z., Yuksel, N., Kula, S., Akman, A., \& Hasanreisoglu, B Childhood glaucoma as an ophthalmic manifestation of Seckel syndrome. J. Glaucoma 22, e3-4 (2013).

[17] Al-Dosari, M. S., Shaheen, R., Colak, D., \& Alkuraya, F. S. Novel CENPJ mutation causes Seckel syndrome. J. Med. Genet. 47, 411-414 (2010).

[18] Arslan, D., et al. A case of Seckel syndrome with tricuspid atresia. Genet. Couns. Geneva Switz. 25, 171-175 (2014).

[19] Brackeen, A., Babb-Tarbox, M., \& Smith, J. Pigmentary changes and atopic dermatitis in a patient with Seckel syndrome. Pediatr. Dermatol. 24, 53-56 (2007).

[20] Butler, M. G., Hall, B. D., Maclean, R. N., \& Lozzio, C. B. Do some patients with Seckel syndrome have hematological problems and/or chromosome breakage? Am. J. Med. Genet. 27, 645-649 (1987).

[21] Can, E., et al. A case of Seckel syndrome with Tetralogy of Fallot. Genet. Couns. Geneva Switz. 21, 49-51 (2010).

[22] Capovilla, G., et al. Seckel's syndrome and malformations of cortical development: report of three new cases and review of the literature. J. Child Neurol. 16, 382-386 (2001).

[23] Panigrahi, I., Kaur, S., Kulkarni, K., Das, R., \& Marwaha, R. K. Seckel syndrome with chromosomal 18 deletion. Indian $J$. Pediatr. 76, 1270-1271 (2009).

[24] Griffith, E., et al. Mutations in pericentrin cause Seckel syndrome with defective ATR-dependent DNA damage signaling. Nat. Genet. 40, 232-236 (2008).

[25] Ogi, T., et al. Identification of the first ATRIP-deficient patient and novel mutations in ATR define a clinical spectrum for ATR-ATRIP Seckel Syndrome. PLoS Genet. 8, e1002945 (2012).

[26] Shaheen, R., Al Tala, S., Almoisheer, A., \& Alkuraya, F. S. Mutation in PLK4, encoding a master regulator of centriole formation, defines a novel locus for primordial dwarfism. $J$. Med. Genet. 51, 814-816 (2014).

[27] Goodship, J., et al. Autozygosity mapping of a seckel syndrome locus to chromosome 3q22. 1-q24. Am. J. Hum. Genet. 67, 498-503 (2000).

[28] Grewal, A., et al. Palatoplasty in a patient with Seckel syndrome: an anesthetic challenge. Braz. J. Anesthesiol.
Elsevier 64, 216-218 (2014).

[29] Kilinç, M. O., et al. Is the novel SCKL3 at 14q23 the predominant Seckel locus? Eur. J. Hum. Genet. EJHG 11, 851857 (2003)

[30] Shanske, A., Caride, D. G., Menasse-Palmer, L., Bogdanow, A., \& Marion, R. W. Central nervous system anomalies in Seckel syndrome: report of a new family and review of the literature. Am. J. Med. Genet. 70, 155-158 (1997).

[31] Willems, M., et al. Molecular analysis of pericentrin gene (PCNT) in a series of $24 \mathrm{Seckel} /$ microcephalic osteodysplastic primordial dwarfism type II (MOPD II) families. J. Med. Genet. 47, 797-802 (2010).

[32] Abou-Zahr, F., et al. Normal expression of the Fanconi anemia proteins FAA and FAC and sensitivity to mitomycin C in two patients with Seckel syndrome. Am. J. Med. Genet. 83, 388391 (1999).

[33] Kalay, E., et al. CEP152 is a genome maintenance protein disrupted in Seckel syndrome. Nat. Genet. 43, 23-26 (2011).

[34] Kutlu, R., Alkan, A., Kutlu, O., \& Yakinci, C. Seckel syndrome with polyarteritis nodosa. Indian Pediatr. 41, 1158-1161 (2004).

[35] Sorof, J. M., Dow-Smith, C., \& Moore, P. J. Severe hypertensive sequelae in a child with Seckel syndrome (bird-like dwarfism). Pediatr. Nephrol. Berl. Ger. 13, 343-346 (1999).

[36] Kumar, R., Rawal, M., Agarwal, S., \& Gathwala, G. Semilobar holoprosencephaly in Seckel syndrome. Indian J. Pediatr. 75, 519-520 (2008).

[37] Cherian, M. P. Seckel-like syndrome or Seckel variants? Ann. Saudi Med. 24, 469-472 (2004).

[38] Sophie, S., \& Ahmed, T. Dialysis access surgery with Seckel syndrome. Paediatr. Anaesth. 16, 804-805; author reply 805-806 (2006).

[39] Yigit, G., et al. Mutations in CDK5RAP2 cause Seckel syndrome. Mol. Genet. Genomic Med. 3, 467-480 (2015).

[40] Di Bartolomeo, R., et al. Malignant hypertension and cerebral haemorrhage in Seckel syndrome. Eur. J. Pediatr. 162, 860$862(2003)$.

[41] Brancati, F., Castori, M., Mingarelli, R., \& Dallapiccola, B. Majewski osteodysplastic primordial dwarfism type II (MOPD II) complicated by stroke: clinical report and review of cerebral vascular anomalies. Am. J. Med. Genet. A. 139, 212-215 (2005).

[42] Majewski, F., \& Goecke, T. O. Microcephalic osteodysplastic primordial dwarfism type II: report of three cases and review. Am. J. Med. Genet. 80, 25-31 (1998).

[43] Shebib, S., Hugosson, C., Sakati, N., \& Nyhan, W. L. Osteodysplastic variant of primordial dwarfism. Am. J. Med. Genet. 40, 146-150 (1991).

[44] Spranger, S., et al. Case report. Microcephalic osteodysplastic primordial dwarfism type II: a child with unusual symptoms and clinical course. Eur. J. Pediatr. 155, 796-799 (1996).

[45] Masuno, M., et al. Osteodysplastic primordial dwarfism: a case with features of type II. Clin. Dysmorphol. 4, 57-62 (1995). 
[46] Galasso, C., Lo-Castro, A., Lalli, C., Cerminara, C., \& Curatolo, P. Neurologic aspects of microcephalic osteodysplastic primordial dwarfism type II. Pediatr. Neurol. 38, 435-438 (2008).

[47] Piane, M., et al. Majewski osteodysplastic primordial dwarfism type II (MOPD II) syndrome previously diagnosed as Seckel syndrome: report of a novel mutation of the PCNT gene. Am. J. Med. Genet. A. 149A, 2452-2456 (2009).

[48] Kantaputra, P. N. Apparently new osteodysplastic and primordial short stature with severe microdontia, opalescent teeth, and rootless molars in two siblings. Am. J. Med. Genet. $111,420-428$ (2002).

[49] Kilic, E., et al. A novel mutation in RNU4ATAC in a patient with microcephalic osteodysplastic primordial dwarfism type I. Am. J. Med. Genet. A. 167A, 919-921 (2015).

[50] Vichi, G. F., Currarino, G., Wasserman, R. L., Duvina, P. L., \& Filippi, L. Cephaloskeletal dysplasia (Taybi-Linder syndrome: osteodysplastic primordial dwarfism type III): report of two cases and review of the literature. Pediatr. Radiol. 30, 644-652 (2000).

[51] Abdel-Salam, G. M. H., et al. A homozygous mutation in RNU4ATAC as a cause of microcephalic osteodysplastic primordial dwarfism type I (MOPD I) with associated pigmentary disorder. Am. J. Med. Genet. A. 155A, 2885-2896 (2011).

[52] Abdel-Salam, G. M. H., et al. Further delineation of the clinical spectrum in RNU4ATAC related microcephalic osteodysplastic primordial dwarfism type I. Am. J. Med. Genet. A. 161 A, 18751881 (2013).

[53] Klinge, L., Schaper, J., Wieczorek, D., \& Voit, T. Microlissencephaly in microcephalic osteodysplastic primordial dwarfism: a case report and review of the literature. Neuropediatrics 33, 309-313 (2002).

[54] Abdel-Salam, G. M. H., et al. Expanding the phenotypic and mutational spectrum in microcephalic osteodysplastic primordial dwarfism type I. Am. J. Med. Genet. A. 158A, 14551461 (2012).

[55] Majewski, F. Caroline Crachami and the delineation of osteodysplastic primordial dwarfism type III, and autosomal recessive syndrome. Am. J. Med. Genet. 44, 203-209 (1992).

[56] Berger, A., et al. Neonatal cholestasis and focal medullary dysplasia of the kidneys in a case of microcephalic osteodysplastic primordial dwarfism. J. Med. Genet. 35, 61-64 (1998).

[57] Abdel-Salam, G. M. H., Emam, B. A., Khalil, Y. M., \& Abdel-Hamid, M. S. Long-term survival in microcephalic osteodysplastic primordial dwarfism type I: Evaluation of an 18 -year-old male with g. $55 \mathrm{G}>\mathrm{A}$ homozygous mutation in RNU4ATAC. Am. J. Med. Genet. A. 170A, 277-282 (2016).

[58] Deniz, K., Kontaş, O., \& akçakuș, M. Neonatal hepatitis in 2 siblings with Seckel syndrome. Pediatr. Dev. Pathol. Off. J. Soc. Pediatr. Pathol. Paediatr. Pathol. Soc. 9, 81-85 (2006).

[59] Sarici, D., Akin, M. A., Kara, A., Doganay, S., \& Kurtoglu, S. Seckel syndrome accompanied by semilobar holoprosencephaly and arthrogryposis. Pediatr. Neurol. 46, 189-191 (2012).

[60] Krishna, A. G., Scrimgeour, E. M., \& Zawawi, T. H. Seckel syndrome in a Yemeni family in Saudi Arabia. Am. J. Med. Genet. 51, 224-227 (1994).

[61] Hopkins, T. E., \& Haines, S. J. Rapid development of Chiari I malformation in an infant with Seckel syndrome and craniosynostosis. Case report and review of the literature. $J$. Neurosurg. 98, 1113-1115 (2003).

[62] Thapa, R., Mallick, D., Biswas, B., \& Ghosh, A. Open and closed lip schizencephaly in Seckel syndrome: a case report. $J$. Child Neurol. 25, 494-496 (2010).

[63] Howanietz, H., Frisch, H., Jedlicka-Köhler, I., \& Steger, H. Seckel dwarfism based on a personal case. Klin. Padiatr. 201, 139-141 (1989).

[64] Fitzgerald, B., O’Driscoll, M., Chong, K., Keating, S., \& Shannon, P. Neuropathology of fetal stage Seckel syndrome: a case report providing a morphological correlate for the emerging molecular mechanisms. Brain Dev. 34, 238-243 (2012).

[65] Engel, M., et al. Cranial vault remodeling in microcephalic osteodysplastic primordial dwarfism type II and craniosynostosis. J. Craniofac. Surg. 23, 1407-1409 (2012).

[66] Fukuzawa, R., et al. Autopsy case of microcephalic osteodysplastic primordial 'dwarfism' type II. Am. J. Med. Genet. 113, 93-96 (2002).

[67] Unal, Y., Dogan, A. T., Ozkose, Z., \& Koksal, F. Anesthetic management of a patient with Seckel syndrome and implanted pacemaker. Paediatr. Anaesth. 18, 676-677 (2008).

[68] Halder, A., et al. Osteodysplastic primordial dwarfism type II with normal intellect but delayed central nervous system myelination. Am. J. Med. Genet. 80, 12-15 (1998).

[69] Kiran, Z., Furqan, S., Farooq, S., \& Rashid, O. Microcephalic (majewski) osteodysplastic primordial dwarfism type ii with severe hyperandrogenism. AACE Clin. Case Rep. 3, e166-e169 (2016).

[70] Pierce, M. J., \& Morse, R. P. The neurologic findings in Taybi-Linder syndrome (MOPD I/III): case report and review of the literature. Am. J. Med. Genet. A. 158A, 606-610 (2012).

[71] Shaheen, R., et al. Mutation in WDR4 impairs tRNA m (7) G46 methylation and causes a distinct form of microcephalic primordial dwarfism. Genome Biol. 16, 210 (2015).

[72] Codd, P. J., Scott, R. M., \& Smith, E. R. Seckel syndrome and moyamoya. J. Neurosurg. Pediatr. 3, 320-324 (2009).

[73] D'Angelo, V. A., Ceddia, A. M., Zelante, L., \& Florio, F. P. Multiple intracranial aneurysms in a patient with Seckel syndrome. Childs Nerv. Syst. ChNS Off. J. Int. Soc. Pediatr. Neurosurg. 14, 82-84 (1998).

[74] Rahme, R., Crevier, L., Dubois, J., \& Mercier, C. Moyamoya-like vasculopathy and Seckel syndrome: just a coincidence? Childs Nerv. Syst. ChNS Off. J. Int. Soc. Pediatr. Neurosurg. 26, 983-986 (2010).

[75] Bober, M. B., et al. Majewski osteodysplastic primordial dwarfism type II (MOPD II): expanding the vascular phenotype. Am. J. Med. Genet. A. 152A, 960-965 (2010).

[76] Kannu, P., Kelly, P., \& Aftimos, S. Microcephalic osteodysplastic primordial dwarfism type II: a child with café au lait lesions, cutis marmorata, and moyamoya disease. Am. J. Med. Genet. A. 128A, 98-100 (2004). 
[77] Waldron, J. S., et al. Multiple intracranial aneurysms and moyamoya disease associated with microcephalic osteodysplastic primordial dwarfism type II: surgical considerations. J. Neurosurg. Pediatr. 4, 439-444 (2009).

[78] Alkuraya, F. S. Primordial dwarfism: an update. Curr. Opin. Endocrinol. Diabetes Obes. 22, 55-64 (2015).

[79] Qvist, P., et al. CtIP Mutations Cause Seckel and Jawad Syndromes. PLoS Genet. 7, e1002310 (2011).

[80] Sir, J.-H., et al. A primary microcephaly protein complex forms a ring around parental centrioles. Nat. Genet. 43, 1147-1153 (2011).
[81] Harley, M. E., et al. TRAIP promotes DNA damage response during genome replication and is mutated in primordial dwarfism. Nat. Genet. 48, 36-43 (2016).

[82] Dauber, A., et al. Novel microcephalic primordial dwarfism disorder associated with variants in the centrosomal protein ninein. J. Clin. Endocrinol. Metab. 97, E2140-2151 (2012).

[83] Karatas, A. F., et al. Hip pathology in Majewski osteodysplastic primordial dwarfism type II. J. Pediatr. Orthop. 34, 585-590 (2014).

[84] Edery, P., et al. Association of TALS developmental disorder with defect in minor splicing component U4atac snRNA. Science 332, 240-243 (2011). 